\title{
Factors associated with oesophagogastric cancers missed by gastroscopy: a case-control study
}

\author{
Foong Way David Tai (D) , Nicholas Wray, Reena Sidhu, Andrew Hopper, \\ Mark McAlindon
}

Academic Department of Gastroenterology and Hepatology, Royal Hallamshire Hospital, Sheffield Teaching Hospitals NHS Foundation Trust, Sheffield, UK

\section{Correspondence to} Dr Foong Way David Tai, Academic Unit of Gastroenterology and Hepatology, Sheffield S10 2JF, UK; david.tai@nhs.net

Received 26 February 2019 Revised 27 June 2019 Accepted 30 June 2019 Published Online First 11 July 2019

\section{Check for updates}

(C) Author(s) (or their employer(s)) 2020. No commercial re-use. See rights and permissions. Published by BMJ.

To cite: Tai FWD,

Wray N, Sidhu R, et al.

Frontline Gastroenterology

2020;11:194-201.

\begin{abstract}
Introduction There is increasing demand for gastroscopy in the United Kingdom. In around $10 \%$ of patients, gastroscopy is presumed to have missed oesophagogastric (OG) cancer prior to diagnosis. We examine patient, endoscopist and service level factors that may affect rates of missed OG cancers.

Methods Gastroscopies presumed to have missed OG cancers performed up to 3 years prior to diagnosis were identified over 6 years in Sheffield, UK. Factors related to the patient, endoscopist and endoscopy lists were examined in a casecontrol study. Procedures which missed cancer were compared with two procedure controls: the procedures which subsequently diagnosed cancer in the same patient, and second, endoscopist matched procedures diagnostic of small benign focal lesions.
\end{abstract}

Results We identified 48 (7.7\%) cases of missed OG cancer. Endoscopy lists on which OG cancer diagnoses were missed contained a greater number of total procedures compared with lists on which diagnoses were subsequently made (OR 1.42 95\% Cl 1.13 to 1.78) and when compared with lists during which matched endoscopists diagnosed benign small focal lesions (OR $1.25,95 \% \mathrm{Cl} 1.02$ to 1.52 ). The use of sedation, endoscopist profession and experience, or time of procedure were not associated with a missed cancer.

Conclusion $7.7 \%$ of patients diagnosed with OG cancer could have been diagnosed and treated earlier. Our study suggests that endoscopy lists with greater numbers of procedures may be associated with missed OG cancers. The use of sedation, endoscopist background or time of procedure did not increase the risk of missed cancer procedures.

\section{INTRODUCTION}

Gastroscopy is the most common procedure performed in gastrointestinal

\section{Significance of this study}

What is already known on this topic

- Approximately $10 \%$ of patients diagnosed with oesophagogastric cancer have had a gastroscopy within the preceding 3 years. These examinations are considered likely to have missed early cancer diagnoses. The time spent during endoscopic examination correlates with the likelihood of detecting high risk lesions or neoplasia.

\section{What this study adds}

- Greater numbers of procedures on endoscopy lists were associated with a risk of missed cancer diagnosis. No associations between use of sedation, endoscopist experience and time of day of gastroscopy and risk of missed cancer were found.

\section{How might it impact on clinical practice in the foreseeable future \\ - Endoscopic examination times should be monitored to ensure that service pressures do not have a negative impact on diagnostic yield.}

endoscopy units, ${ }^{1}$ and there has been an over $40 \%$ increase in gastroscopies and over $80 \%$ increase in colonoscopies performed in the UK in the last 10 years. ${ }^{2}$ These gastroscopies are normal or yield benign pathology in the majority, however oesophagogastric (OG) cancer is diagnosed in between $1 \%$ and $2 \%$, depending on the indication of procedure, and diagnostic yield has remained relatively static. ${ }^{3}$ The discriminative value of upper gastrointestinal alarm symptoms however are poor and this might explain why OG cancers are diagnosed in the later stages (tumour, node, metastases (TNM) classification 3 and 4) in three quarters of patients, ${ }^{45}$ up to a third of patients are 
diagnosed after an emergency admission and less than $40 \%$ have treatment with curative intent. ${ }^{67}$

It is well recognised that colorectal cancers may be diagnosed shortly after a reportedly normal colonoscopy and a similar situation exists in OG cancer: between $5.3 \%$ and $13.9 \%$ of patients with OG malignancy in the Western population ${ }^{8-14}$ have had normal gastroscopies reported within the previous 3 years. Based on studies of cancer biology which suggest that the doubling time of an early gastric cancer is between 2 and 3 years, ${ }^{15}$ gastroscopy is considered to have definitely missed a cancer if performed in the year before diagnosis and possibly missed a cancer if done within the previous 3 years. ${ }^{10}$ Reasons for missed cancers are unclear and the subject of much interest. Cases of missed OG cancer may be associated with the presence of alarm symptoms, ${ }^{10}{ }^{12}$ more likely to be females under the age of 55 years in gastric cancer ${ }^{4}$ and have early disease (TNM classification T $0 / 1$ ) on diagnosis. ${ }^{45}$

Up to $70 \%$ of procedures presumed to have missed cancers describe abnormalities at the site of malignancy identified at the subsequent diagnostic procedure. ${ }^{10} 12$ Studies have suggested that performing procedures quickly increases the risk of missed pathology. ${ }^{16} 17$ Endoscopist's experience is clearly associated with colonic polyp detection rate, ${ }^{18-20}$ and there is some evidence that experience is associated with better diagnostic capability in gastroscopy. ${ }^{21} 22$ The use of sedation during endoscopic procedures may well improve overall patient satisfaction and willingness to have a repeat gastroscopy but whether diagnostic quality improves with sedation is unknown. ${ }^{23-26}$ Finally, service level factors such as endoscopy list composition and workload are often out of control of the endoscopist and may conceivably influence missed procedures owing to pressures of service provision and endoscopist fatigue. ${ }^{27}$

In this case-control study, we investigate whether patient, endoscopist or service level factors are associated with missed OG cancer diagnoses.

\section{METHODS}

Patients diagnosed with OG cancer between January 2012 and December 2017 were identified from a local cancer database (Infoflex V.5, Chameleon Information Management Systems) for the population of Sheffield, UK, using International Classification of Diseases 15 and 16 codes. Gastroscopies performed on these patients with OG cancer between January 2009 and December 2017 at Sheffield Teaching Hospitals (Northern General Hospital and Royal Hallamshire Hospital) were examined to identify patients who have had procedures which are presumed to have missed cancer up to 3 years prior to diagnosis. Patients referred from outside Sheffield Teaching Hospitals and those with diagnoses made at planned surveillance (eg, follow-up of gastric or oesophageal ulceration) were excluded. Patients in surveillance programmes were only included if cancer diagnoses were made after referral to investigate new symptoms or anaemia (ie, outwith the surveillance programme).

A case-control study was performed (figure 1). The cases were the procedures performed in the 3 years prior to the diagnoses of OG cancer being made, at which cancers were presumed to have been missed. To determine if the endoscopist, use of sedation or service factors were associated with missed cancers, the cases were compared with two control groups.

The first controls (control 1) were matched for the patient and examined differences between endoscopists related to professional background (gastroenterologist, surgeon or nurse), training status and experience (procedural volume). They comprised the procedures done on the same patient at their subsequent gastroscopy at which OG cancer was diagnosed (and which was performed by a different endoscopist in all cases). Trainee endoscopists were those who were supervised during the procedure by UK Joint Advisory Group (JAG) certified independent endoscopists. The number of gastroscopies performed by an endoscopist between January 2008 and the procedure in question were divided by the months elapsed to measure endoscopists' procedural volume.

Most OG cancers are advanced at the time of diagnosis. Endoscopists performing procedures presumed to have missed early cancer by definition would have missed smaller, more subtle lesions. It might be that these endoscopists are insufficiently skilled at detecting small or subtle mucosal abnormalities. Therefore, the second control group (control 2) comprised procedures at which small $(<10 \mathrm{~mm})$ benign focal lesions were detected. These procedures were performed by the same endoscopist who performed the case procedure presumed to have missed OG cancer to control for heterogeneity between endoscopists. Patients selected were matched to missed cancer procedure for age, gender and location of pathology. The aim was to examine service factors which might affect outcome.

The variation in number and types of procedures performed during a standard 4-hour endoscopy session was used as a surrogate marker for the workload of endoscopists. In addition, this is also presented using a point system (one point equivalent to a $20 \mathrm{~min}$ unit of time), described by the UK JAG. ${ }^{128}$ Gastroscopy is assigned one point; colonoscopy, two points; a planned therapeutic intervention attracts an additional point and both endoscopic retrograde cholangiopancreatography and endoscopic ultrasound acquire three points.

Finally, among the cohort of patients with OG cancer, differences in patient factors such as gender, age, indication for gastroscopy and anatomical location of cancer were examined between patients with and without a missed cancer procedure. 


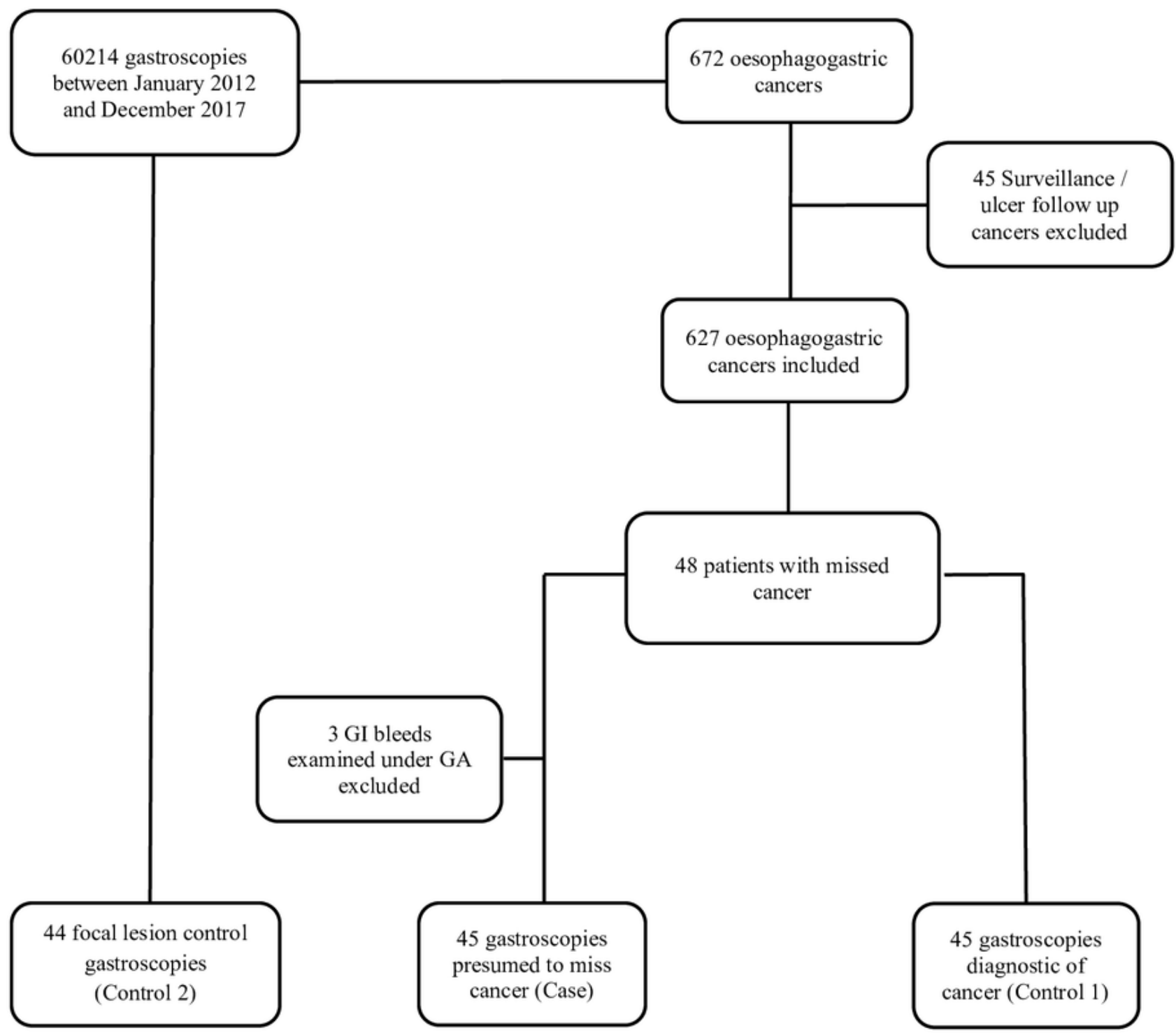

Figure 1 Selection of the cases and control groups used to investigate factors contributing to the risk of cancer diagnoses being missed at gastroscopy. Control group 1 comprises procedures at which cancer was diagnosed following a previous non-diagnostic procedure. Control group 2 comprises procedures at which endoscopists who were considered to have missed early cancers identified small benign lesions. GA, general anaesthetic.

Data were analysed using SPSS (V.23.0.0). Continuous data are presented as mean $( \pm S D)$ or median (IQR) and categorical variables and their difference are presented as a frequency (\%) and $\chi^{2}$ (or exact) tests. Binary logistic regression was used to examine potential factors contributing to missed cancer procedures when compared with controls. Significant values $(\mathrm{p}<0.05)$ are reported as ORs with $95 \%$ CIs.

\section{RESULTS}

A total of 60214 gastroscopies were performed between January 2012 and December 2017. We identified 627 patients diagnosed with oesophageal $(50.9 \%)$ and gastric $(48.8 \%)$ cancer during this period having excluded 45 cancers diagnosed on surveillance or follow-up gastroscopies. Forty-eight (7.7\%) were presumed to have had early cancers missed at gastroscopy performed in the preceding 3 years in the oesophagus in 20 patients $(5.9 \%$ of oesophageal cancers) and in the stomach in 28 patients $(8.4 \%$ of gastric cancers). These procedures were performed within 1 year in $2.9 \%$ and between one and 3 years in $4.8 \%$ prior to diagnosis $(1.9 \%$ and $5.2 \%$ for oesophageal cancer and $3.9 \%$ and $4.6 \%$ for gastric cancer respectively). The procedures were performed by 35 endoscopists, nine of which missed more than one cancer. OG cancer and procedures at which cancers were presumed missed represent 1.0\% (627/60214) and $0.08 \%(48 / 60214)$ of all gastroscopies performed during the study period, respectively.

Procedures in which the endoscopists missed cancers were compared with two groups of control procedures (figure 1). Three patients with missed cancer presented as upper GI bleeds requiring emergency endoscopy in 
Table 1 Procedures at which cancer was presumed missed (case) compared with procedures subsequently diagnosing cancer (control 1) and matched procedures at which benign focal lesions were identified (control 2)

\begin{tabular}{|c|c|c|c|c|c|}
\hline & \multirow{2}{*}{$\begin{array}{l}\text { Case: presumed } \\
\text { missed cancer } \\
\text { diagnosis }\end{array}$} & \multicolumn{2}{|c|}{$\begin{array}{l}\text { Control 1: subsequent cancer } \\
\text { diagnosis }\end{array}$} & \multicolumn{2}{|c|}{ Control 2: benign focal lesions } \\
\hline & & & OR $(95 \% \mathrm{Cl})$ & & OR $(95 \% \mathrm{Cl})$ \\
\hline N & 45 & 45 & & 44 & \\
\hline Xylocaine, n (\%) & $45(100)$ & $44(97.8)$ & & $44(100.0)$ & \\
\hline Sedation, n (\%) & $11(24.4)$ & $19(42.2)$ & $2.26(0.92$ to 5.56$)$ & $10(22.7)$ & $1.1(0.43$ to 3.02$)$ \\
\hline \multicolumn{6}{|l|}{ Professional background, n (\%) } \\
\hline Gastroenterologist & $27(62.8)$ & $27(62.8)$ & Reference & & \\
\hline Surgeon & $10(23.3)$ & $14(32.6)$ & $0.71(0.27$ to 1.89$)$ & & \\
\hline Other (nurse/radiologist/GP) & $6(14.0)$ & $2(4.7)$ & $3.00(0.56$ to 16.21$)$ & & \\
\hline Performed by trainee, $\mathrm{n}(\%)$ & $7(16.3)$ & $7(16.3)$ & $1.00(0.32$ to 3.14$)$ & & \\
\hline Mean procedure performed per month & $26(20.5)$ & $25(15.7)$ & $1.00(0.98$ to 1.03$)$ & & \\
\hline \multicolumn{6}{|l|}{ Endoscopy list } \\
\hline Procedures per list, mean (SD) & $8.5(2.0)$ & $7.1(2.0)$ & $1.42(1.13$ to 1.78$)$ & $7.4(2.5)$ & 1.25 (1.02 to 1.52$)$ \\
\hline Points per list, mean (SD) & $9.4(1.4)$ & $8.2(1.7)$ & 1.64 (1.21 to 2.22$)$ & $8.5(2.0)$ & 1.36 (1.03 to 1.78$)$ \\
\hline Only diagnostic gastroscopy performed, $n$ (\%) & $29(64.4)$ & $19(42.8)$ & $2.48(1.06$ to 5.80$)$ & $27(61.4)$ & $1.27(0.51$ to 2.91$)$ \\
\hline Any colonoscopies performed, $\mathrm{n}(\%)$ & $10(22.2)$ & $15(35.6)$ & $0.52(0.20$ to 1.31$)$ & $12(27.3)$ & $0.78(0.30$ to 2.10$)$ \\
\hline Any sigmoidoscopies performed, $\mathrm{n}(\%)$ & $8(17.8)$ & $13(28.9)$ & $0.53(0.20$ to 1.45$)$ & $6(13.6)$ & 1.41 (0.44 to 4.50$)$ \\
\hline Any therapeutics performed, $n(\%)$ & $5(11.1)$ & $10(22.2)$ & $0.44(0.14$ to 1.40$)$ & $7(15.9)$ & 0.53 (0.14 to 1.95$)$ \\
\hline Time of day (AM), n (\%) & $25(55.6)$ & $26(57.8)$ & $0.91(0.39$ to 2.10$)$ & $17(38.6)$ & 1.91 (0.82 to 4.45$)$ \\
\hline Last procedure on list, $n$ (\%) & $5(11.1)$ & $1(2.2)$ & 5.50 (0.62 to 49.11$)$ & $4(9.1)$ & $1.28(0.32$ to 5.13$)$ \\
\hline Latter half of list, $n(\%)$ & $34(75.6)$ & $34(75.6)$ & $1.00(0.38$ to 2.61$)$ & $37(84.1)$ & 0.64 (0.22 to 1.88$)$ \\
\hline
\end{tabular}

theatres and were excluded from analysis. Procedures at which a cancer diagnosis was made following a reportedly normal gastroscopy (control 1) were performed a median of 558 (IQR 635) days after the missed cancer procedure with no difference in median times between those diagnosed with gastric and oesophageal cancers $(p=0.09)$. A greater number of procedures (OR 1.42), greater total number of points on the endoscopy list (OR 1.64) and lists where only diagnostic gastroscopies were performed (OR 2.48) were associated with a risk of missing cancer (table 1). The use of sedation, endoscopist factors or time of day of procedure did not increase the risk of missed cancer procedures.

Procedures diagnostic of benign focal lesions (control 2) matched to the endoscopist performing the missed cancer procedure were identified in $44 / 45$ patients. In the oesophagus, these lesions were ulcers $(n=4)$, submucosal lesions $(n=2)$, polyps $(n=5)$, nodules $(n=5)$, a raised lesion $(n=1)$, an erosion $(n=1)$, an oesophageal varix with red spot $(n=1)$ and an endoscopic mucosal resection (EMR) scar $(n=1)$. In the stomach, these lesions were polyps $(\mathrm{n}=8)$, ulcers $(n=4)$, erosions $(n=5)$, nodules $(n=2)$, angioectasias $(n=2)$, a gastric varix with red sign $(n=1)$, a healed gastric ulcer scar $(n=1)$ and an EMR scar $(n=1)$. These procedures were performed a median of 22 (IQR 125) days after the missed cancer procedure. A greater total number of procedures (OR 1.25) and number of points on the endoscopy lists (OR 1.36) were associated with a risk of missing cancer (table 1).
Characteristics of patients considered to have missed cancers were compared with the cohort of patients without missed cancer $(n=578)$ in table 2 . There were more cases of missed gastric cancer in male patients (OR 3.0, 95\% CI 1.32 to 6.91) and potentially fewer cases among those who were examined for anaemia (OR $0.23,95 \% \mathrm{CI} 0.05$ to 1.01 ). There were fewer cases of missed oesophageal cancer among those who were examined for dysphagia (OR 0.16, 95\% CI 0.05 to 0.50 ), but more cases among those examined for anaemia (OR 5.36, 95\% CI 1.87 to 15.41 ).

\section{DISCUSSION}

In this retrospective single-centre case-control study, 627 patients were diagnosed with OG cancer and 48 cases $(7.7 \%)$ comprised non-diagnostic procedures performed on patients in the 3 years prior to their OG cancer diagnosis. When these cases were compared with two control groups of procedures matched either for the patient or for the endoscopist, only the number of procedures and number of points on a list was associated with missed cancers. Endoscopy lists with procedures where cancer was presumed to be missed had on average one additional procedure compared with lists where cancer or benign focal lesions were diagnosed. Use of sedation, endoscopist professional background or procedural experience, time of day or when the procedure was performed on the list did not affect the outcome. 
Table 2 Comparison of patients with oesophagogastric cancer with and without missed cancer procedures

\begin{tabular}{|c|c|c|c|c|c|c|c|}
\hline & \multirow[t]{2}{*}{ Overall } & \multicolumn{3}{|c|}{ Oesophageal Cancer } & \multicolumn{3}{|c|}{ Gastric Cancer } \\
\hline & & Not missed & Missed & $P$ value & Not missed & Missed & $P$ value \\
\hline $\mathrm{n}(\%)$ & 627 & $319(94.1)$ & $20(5.9)$ & & $305(91.6)$ & $28(8.4)$ & \\
\hline Age, mean (SD) & $72.1(12.0)$ & $70.9(11.9)$ & $74.3(8.5)$ & 0.22 & $73.7(12.2)$ & $71.8(11.5)$ & 0.45 \\
\hline Female gender, n (\%) & $446(66.4)$ & $92(30.8)$ & $6(30.0)$ & 0.94 & $97(34.6)$ & $16(61.5)$ & 0.01 \\
\hline \multicolumn{8}{|l|}{ Indication for gastroscopy } \\
\hline Dysphagia, n (\%) & $236(40.4)$ & $172(60.6)$ & $4(20.0)$ & 0.001 & $55(21.7)$ & $5(19.2)$ & 0.77 \\
\hline Anaemia, n (\%) & $96(16.4)$ & $21(7.4)$ & $6(30.0)$ & 0.005 & $67(26.4)$ & $2(7.7)$ & 0.03 \\
\hline Loss of weight, n (\%) & $75(12.8)$ & $33(11.6)$ & $3(15.0)$ & 0.65 & $38(15.0)$ & $1(3.8)$ & 0.12 \\
\hline Dyspepsia, n (\%) & $126(21.6)$ & $41(14.4)$ & $5(25.0)$ & 0.20 & $70(27.6)$ & $10(38.5)$ & 0.24 \\
\hline Vomiting, n (\%) & $5(0.9)$ & $2(0.7)$ & $0(0.0)$ & 0.70 & $2(0.8)$ & $1(3.8)$ & 0.15 \\
\hline Gl bleed, n (\%) & $53(9.1)$ & $15(5.3)$ & $1(5.0)$ & 0.96 & $33(13.0)$ & $4(15.4)$ & 0.73 \\
\hline Imaging abnormality, n (\%) & $51(8.2)$ & $19(6.4)$ & $1(5.0)$ & - & $28(10.0)$ & $3(11.5)$ & - \\
\hline \multicolumn{8}{|l|}{ Location of cancer } \\
\hline Oesophagus & & & & 0.45 & & & \\
\hline Upper, n (\%) & $11(3.4)$ & $11(3.4)$ & $1(5.0)$ & & & & \\
\hline Middle, n (\%) & $61(19.1)$ & $55(18.4)$ & $6(30.0)$ & & & & \\
\hline Lower, n (\%) & $204(63.9)$ & $192(64.2)$ & $12(60.0)$ & & & & \\
\hline Unspecified, n (\%) & $43(13.5)$ & $42(14.0)$ & $1(5.0)$ & & & & \\
\hline Gastric & & & & & & & 0.76 \\
\hline Cardia, n (\%) & $87(28.4)$ & & & & $77(27.5)$ & $10(38.5)$ & \\
\hline Fundus, n (\%) & $17(5.6)$ & & & & $15(5.4)$ & $2(7.7)$ & \\
\hline Body, n (\%) & $75(24.5)$ & & & & $69(24.6)$ & $6(23.1)$ & \\
\hline Antrum, n (\%) & $48(15.7)$ & & & & $45(16.1)$ & $3(11.5)$ & \\
\hline Pylorus, n (\%) & $18(5.9)$ & & & & $18(6.4)$ & $0(0.0)$ & \\
\hline Unspecified, n (\%) & $41(13.4)$ & & & & $38(13.6)$ & $3(11.5)$ & \\
\hline
\end{tabular}

Much of the literature on missed cancer in gastroscopy are cohort studies devoted to establishing incidence of missed cancer and patient factors associated with missed OG cancer occurrences. ${ }^{4} 51012$ Despite up to $70 \%$ reporting visible lesion at gastroscopies that miss cancer, only few studies examine the effect of the endoscopist ${ }^{29} 30$ and no studies examine the effect of service provision pressures, or use of sedation on missed cancer procedures. Time spent on examination increases the sensitivity of gastroscopy, ${ }^{31}$ and we hypothesised therefore that service provision pressures may also have an impact on sensitivity.

By comparing procedures where cancers were missed with those procedures done on the same patient at their subsequent gastroscopy at which OG cancer was diagnosed, we controlled for patient factors (age, gender, anatomical location) and examined endoscopist and service provision factors which could be contributing to cases of missed OG cancer. We found that number of procedures performed on lists were associated with a risk of missing cancer. However, it could be argued that the size of the lesion or endoscopist skill could be the primary determinant of whether or not cancer was detected. Therefore, a second control group of procedures matched for the endoscopist that performed the non-diagnostic (missed cancer) procedure in which identified small benign focal lesions were compared, to control for size of lesion and endoscopists' ability. The size of the missed lesions cannot be known but it seems reasonable to assume they were small, so matched controls in the second control group were procedures in which benign focal lesions of less than $10 \mathrm{~mm}$ were detected. In this second control group, the association of missed OG cancer and number of total procedures on the endoscopy list was also found. This finding therefore may suggest that increasing pressures in endoscopy lists may have a negative impact on the detection of early cancer.

The sensitivity of endoscopic procedures relates to inspection time. ${ }^{16} 1731$ Teh and collaborators ${ }^{31}$ have shown that gastroscopist with procedure times of more than $7 \mathrm{~min}$ had an over two-fold (OR 2.50; 95\% CI 1.52 to 4.12) diagnostic yield of high risk lesions and an over threefold yield of gastric neoplasia (OR 3.42 ; $95 \%$ CI 1.25 to 10.38 ) than those performing shorter examinations. ${ }^{31} \mathrm{~A}$ survey of colonoscopists has suggested that increasing workloads have in some instances resulted in negative changes in practice, including reducing withdrawal times in colonoscopy. ${ }^{27}$ It is therefore conceivable that increasing workload has a negative impact on gastroscopists examination times or thoroughness of examination.

It is however, the activity between procedures which takes most of the time during an endoscopy list: the 
turnaround time, defined as time between the extubation of one patient and intubation of the next. ${ }^{32} 33$ In the UK centres, Bryce et $a l^{32}$ reported that in 169 patients across 43 endoscopy lists, mean turnover time per patient was $20.8 \mathrm{~min}$ and Edmondson et $a l^{33}$ reported a similar turnover time of $20 \mathrm{~min}$, after implementing nurse-led consent and intravenous cannulation. ${ }^{32} 33$ In Ontario, Canada, where conscious sedation is used routinely, the patients spend on average a total of $23 \mathrm{~min}$ in the endoscopy room before and after the procedure. ${ }^{34}$ Therefore, further increase in endoscopy activity might be achieved by improving workflow efficiencies and reducing turnaround time, without having a negative impact on examination time. However, although our study did not demonstrate an association between the time of day of procedure or the position on endoscopy list and missed cancer occurrence, colorectal adenoma detection rates have been shown to decline as time passes in the day suggesting that endoscopist fatigue and attention span may affect performance. ${ }^{35}$ It is likely, however, that our study is not adequately powered to address this question. Future studies should consider examination and endoscope turnaround times in conjunction with endoscopy list burden and time of day of procedure.

Our data failed to demonstrate any association between professional background, training grade and volume of gastroscopies performed with missed cancer occurrences. Previous studies comparing gastroenterologists and non-gastroenterologists are inconclusive and endoscopist experience, when measured by number of years' experience, did not affect sensitivity of gastroscopy to detect early gastric cancer. ${ }^{29}{ }^{30} \mathrm{It}$ seems more likely that expertise, based on continuing training and experience, is the main determinant of high quality gastroscopies, rather than professional background or procedural volume per se.

The rate of missed OG cancer reported in our study is in line with recent published UK population cohort studies. ${ }^{45}$ When compared with the rest of the cohort of 581 patients who had cancer diagnosed at first gastroscopy, gastric cancers were missed more commonly in female patients, consistent with UK cohorts. ${ }^{4}$ In our cohort of patients with OG cancer, oesophageal cancers were missed more commonly when performed for anaemia, but less commonly when performed for dysphagia. A large retrospective cohort study of 28064 gastroscopies from Australia report 55 cases of missed OG cancers (7.8\%) among 706 OG cancers over 14 years. ${ }^{10}$ This study from Australia suggested that gastroscopies performed for dysphagia was associated with an increased risk of missed cancer. In our cohort of patients with oesophageal cancer, however, patients with dysphagia were more likely to have not been missed, likely reflecting more advanced disease than in those where oesophageal cancer was missed initially. On the other hand, we found that in patients examined for anaemia, oesophageal cancer was more commonly missed. Whether or not the cause of the anaemia at the time of initial 'missed' gastroscopy was related to occult oesophageal malignancy is uncertain. In our study, there was no association between use of sedation which might be expected to improve quality of endoscopy. ${ }^{37}$ Although Raftopoulos et al do not specifically report use of sedation in their study, sedated diagnostic gastroscopy is universal practice in Australia, ${ }^{38}$ and a similar rate of missed OG cancer procedures between our study and that of Raftopoulos and collaborators may therefore suggest that sedation does not affect risk of missed cancer procedures.

There are limitations to the study. The number of cases was small, limiting statistical power and CIs, and it cannot be certain that all had visible lesions at the time of the initial non-diagnostic procedure. Procedures presumed to have missed cancer are relatively rare with one occurring every 1250 procedures during our study period, therefore a case-control design was selected to examine for risk factors of missed cancer procedures. The procedural workload of endoscopy lists where cancers were truly excluded are unknown and therefore there is a possibility that this association has occurred due to selection bias. With an increase in demand for endoscopy in the last decade, it may also be that endoscopy lists over the study period have become increasingly populated over time. Endoscopy examination times, known to affect lesion detection rate, were not available and further research is needed to determine if this is affected by number of procedures on a list. Although consecutive cases were included, some cases may have been missed if procedures were performed out of area or in the private sector. Endoscopies of subsequent cancer may not have been performed locally and cancers diagnosed on radiological imaging in patients who did not proceed to endoscopy because of poor physical condition would also not have been included. Nevertheless, these cases are likely to be low given a similar rate of missed cancers found in this study compared with UK cohort studies. $^{45}$

Studies in the future should aim to pool cases of missed cancer procedures to examine the effects of service provision pressure. Future iterations of the UK National Endoscopy Database which include unique patient identifiers could combine both endoscopy procedure and patient level information. ${ }^{39}$ This could potentially allow rates of missed cancer to be computed and examine interactions between endoscopy list burden and endoscopist procedural experience on a much larger scale. This could also provide automated feedback mechanisms, like ones currently being trialled in colonoscopy, to improve quality further. ${ }^{40}$

The implications of this study on service delivery are important. They suggest that endoscopy lists with more procedures is associated risk of missed OG cancer. British and European guidance recommend 
documenting examination times, ${ }^{41}{ }^{42}$ and this study supports this measure to ensure that pressures of service delivery do not result in shorter examination times. Further efforts to improve efficiency in turnaround time may address competing needs to maximise throughput while maintaining examination times. Finally, while this study failed to demonstrate an association between missed cancers and the time of day of procedure, further studies of the effects of list size on endoscopist ability to remain alert and attentive would be beneficial.

\section{CONCLUSION}

In this case-control study, we report that cases of missed OG cancer are associated with greater number of procedures on endoscopy lists, but not use of sedation, experience of endoscopist or time of day of procedure. Our rate of missed OG cancer locally was 7.7\%. Our results support the UK and European Quality standards and improvement initiatives ${ }^{41}{ }^{42}$ in monitoring the duration of gastroscopies to ensure that examination times are adequate and demand does not have a negative impact on quality.

Contributors FWDT wrote the manuscript, designed the study, analysed and collected data. NW collected and analysed data. RS and AH reviewed and critically appraised data and manuscript. MEM wrote the manuscript and designed the study.

Funding The authors have not declared a specific grant for this research from any funding agency in the public, commercial or not-for-profit sectors.

Competing interests None declared.

Patient consent for publication Not required.

Ethics approval This study was approved by the Clinical Effectiveness Unit at Sheffield Teaching Hospitals (CEU reference number 8301 ).

Provenance and peer review Not commissioned; externally peer reviewed.

Data availability statement Data are available upon reasonable request.

\section{ORCID iDs}

Foong Way David Tai http://orcid.org/0000-0002-4272-2007

Mark McAlindon http://orcid.org/0000-0003-0985-3643

\section{REFERENCES}

1 Shenbagaraj L, Thomas-Gibson S, Stebbing J, et al. Endoscopy in 2017: a national survey of practice in the UK. Frontline Gastroenterol 2019;10:7-15.

2 NHS England Statistics. Monthly diagnostics data 2018-19. Available: https://www.england.nhs.uk/statistics/statisticalwork-areas/diagnostics-waiting-times-and-activity/monthlydiagnostics-waiting-times-and-activity/monthly-diagnosticsdata-2018-19/ [Accessed Apr 2019].

3 Ford AC, Marwaha A, Lim A, et al. What is the prevalence of clinically significant endoscopic findings in subjects with dyspepsia? systematic review and meta-analysis. Clin Gastroenterol Hepatol 2010;8:830-7.

4 Chadwick G, Groene O, Riley S, et al. Gastric cancers missed during endoscopy in England. Clin Gastroenterol Hepatol 2015;13:1264-70.

5 Chadwick G, Groene O, Hoare J, et al. A population-based, retrospective, cohort study of esophageal cancer missed at endoscopy. Endoscopy 2014;46:553-60.
6 Markar SR, Mackenzie H, Jemal S, et al. Emergency presentation of esophagogastric cancer: predictors and longterm prognosis. Ann Surg 2018;267:711-5.

7 NHS Digital. National Oesophago-Gastric Cancer Audit 2016, Annual Report, 2016. Available: www.digital.nhs.uk/ catalogue/PUB21561 [Accessed Aug 2018].

8 Khalil Q, Gopalswamy N, Agrawal S. Missed esophageal and gastric cancers after esophagogastroduodenoscopy in a midwestern military veteran population. South Med J 2014;107:225-8.

9 Vradelis S, Maynard N, Warren BF, et al. Quality control in upper gastrointestinal endoscopy: detection rates of gastric cancer in Oxford 2005-2008. Postgrad Med J 2011;87:335-9.

10 Raftopoulos SC, Segarajasingam DS, Burke V, et al. A cohort study of missed and new cancers after esophagogastroduodenoscopy. Am J Gastroenterol 2010;105:1292-7.

11 Bloomfeld RS, Bridgers DI, Pineau BC. Sensitivity of upper endoscopy in diagnosing esophageal cancer. Dysphagia 2005;20:278-82.

12 Yalamarthi S, Witherspoon P, McCole D, et al. Missed diagnoses in patients with upper gastrointestinal cancers. Endoscopy 2004;36:874-9.

13 Amin A, Gilmour H, Graham L, et al. Gastric adenocarcinoma missed at endoscopy. J R Coll Surg Edinb 2002;47:681-4.

14 Menon S, Trudgill N. How commonly is upper gastrointestinal cancer missed at endoscopy? A meta-analysis. Endosc Int Open 2014;02:E46-E50.

15 Fujita S. Biology of early gastric carcinoma. Pathol Res Pract 1978;163:297-309.

16 Barclay RL, Vicari JJ, Doughty AS, et al. Colonoscopic withdrawal times and adenoma detection during screening colonoscopy. N Engl J Med 2006;355:2533-41.

17 Gupta N, Gaddam S, Wani SB, et al. Longer inspection time is associated with increased detection of high-grade dysplasia and esophageal adenocarcinoma in Barrett's esophagus. Gastrointest Endosc 2012;76:531-8.

18 Munroe CA, Lee P, Copland A, et al. A tandem colonoscopy study of adenoma miss rates during endoscopic training: a venture into uncharted Territory. Gastrointest Endosc 2012;75:561-7.

19 Solís-Muñoz P, Solís-Herruzo JA, Rodríguez-Muñoz S. The experience of the endoscopist increases detection rates of smaller size and higher histological grade polyps. $J$ Gastroenterol Hepatol 2014;29:1237-41.

20 James P, Hegagi M, Hegagi M, et al. Variable endoscopist performance in proximal and distal adenoma detection during colonoscopy: a retrospective cohort study. BMC Gastroenterol 2018;18:73.

21 Watanabe K, Nagata N, Shimbo T, et al. Accuracy of endoscopic diagnosis of Helicobacter pyloriinfection according to level of endoscopic experience and the effect of training. BMC Gastroenterol 2013;13:128.

22 Hyun YS, Han DS, Bae JH, et al. Interobserver variability and accuracy of high-definition endoscopic diagnosis for gastric intestinal metaplasia among experienced and inexperienced endoscopists. J Korean Med Sci 2013;28:744-9.

23 Ristikankare M, Hartikainen J, Heikkinen M, et al. Is routine sedation or topical pharyngeal anesthesia beneficial during upper endoscopy? Gastrointest Endosc 2004;60:686-94.

24 Froehlich F, Schwizer W, Thorens J, et al. Conscious sedation for gastroscopy: patient tolerance and cardiorespiratory parameters. Gastroenterology 1995;108:697-704.

25 McQuaid KR, Laine L. A systematic review and meta-analysis of randomized, controlled trials of moderate sedation for routine endoscopic procedures. Gastrointest Endosc 2008;67:910-23.

26 Fisher NC, Bailey S, Gibson JA. A prospective, randomized controlled trial of sedation vs. no sedation in outpatient 
diagnostic upper gastrointestinal endoscopy. Endoscopy 1998;30:21-4.

27 Whitson MJ, Bodian CA, Aisenberg J, et al. Is production pressure jeopardizing the quality of colonoscopy? A survey of U.S. endoscopists' practices and perceptions. Gastrointest Endosc 2012;75:641-8.

28 UK Joint Advisory Group on GI endoscopy. Endoscopy points. Available: https://www.thejag.org.uk/Downloads/General/ Endoscopy\%20points.pptx [Accessed Jun 2019].

29 Wang YR, Loftus, Jr. EV, Judge TA, et al. Rate and predictors of interval esophageal and gastric cancers after esophagogastroduodenoscopy in the United States. Digestion 2016;94:176-80.

30 Hosokawa O, Tsuda S, Kidani E, et al. Diagnosis of gastric cancer up to three years after negative upper gastrointestinal endoscopy. Endoscopy 1998;30:669-74.

31 Teh JL, Tan JR, Lau LJF, et al. Longer examination time improves detection of gastric cancer during diagnostic upper gastrointestinal endoscopy. Clin Gastroenterol Hepatol 2015;13:480-7.

32 Bryce K, Fearn R, Murray S. PTU-086 Improving endoscopy efficiency by reducing turnaround time between cases [10.1136/gutjnl-2018-BSGAbstracts.464]. Gut 2018;67(Suppl 1):A232.

33 Edmondson MJ, Thompson J, Morris J, et al. PWE-139 Audit and Analysis of Turnaround Times in The Endoscopy Suite [10.1136/gutjnl-2016-312388.384]. Gut 2016;65(Suppl 1):A207.

34 Almeida R, Paterson WG, Craig N, et al. A patient flow analysis: identification of process Inefficiencies and workflow metrics at an ambulatory endoscopy unit. Canadian Journal of Gastroenterology and Hepatology 2016;2016:1-7.
35 Sanaka MR, Deepinder F, Thota PN, et al. Adenomas are detected more often in morning than in afternoon colonoscopy. Am J Gastroenterol 2009;104:1659-64. 7.

36 Lee A, Iskander JM, Gupta N, et al. Queue position in the endoscopic schedule impacts effectiveness of colonoscopy. Am J Gastroenterol 2011;106:1457-65.

37 Cohen LB, Ladas SD, Vargo JJ, et al. Sedation in digestive endoscopy: the Athens international position statements. Aliment Pharmacol Ther 2010;32:425-42.

38 Ladas SD, Satake Y, Mostafa I, et al. Sedation practices for gastrointestinal endoscopy in Europe, North America, Asia, Africa and Australia. Digestion 2010;82:74-6.

39 TJW L, Siau K, Esmaily S, et al. Development of a national automated endoscopy database: the United Kingdom national endoscopy database (NED). United European Gastroenterology Journal 2019;2050640619841539.

40 Rutter M. NED-APRIQOT - national endoscopy database: automated performance reports to improve quality outcomes trial 2017. Available: https://www.health.org.uk/researchprojects/ned-apriqot---national-endoscopy-databaseautomated-performance-reports-to-improve

41 Beg S, Ragunath K, Wyman A, et al. Quality Standards in upper gastrointestinal endoscopy: a position statement of the British Society of gastroenterology (Bsg) and association of upper gastrointestinal surgeons of great britain and ireland (AUGIS). Gut 2017;66:1886-99.

42 Bisschops R, Areia M, Coron E, et al. Performance measures for upper gastrointestinal endoscopy: a European Society of gastrointestinal endoscopy (ESGE) quality improvement initiative. Endoscopy 2016;48:843-64. 